\title{
A APLICABILIDADE DE TEXTOS AUTÊNTICOS NO ENSINO-APRENDIZAGEM DA LÍNGUA INGLESA: UMA ABORDAGEM CRÍTICA-REFLEXIVA NO CONTEXTO PÚBLICO DE ENSINO NO BRASIL
}

\author{
THE APPLICABILITY OF AUTHENTIC TEXTS IN THE ENGLISH LANGUAGE \\ TEACHING AND LEARNING: A CRITICAL AND REFLECTIVE APPROACH TO \\ TEACHING PUBLIC CONTEXT IN BRAZIL
}

\author{
Marcelle Santos Rosa Donato ${ }^{1}$ \\ Kanavillil Rajagopalan (Unicamp) ${ }^{2}$
}

\begin{abstract}
Resumo: Este estudo, parte do pressuposto de que ensinar uma língua vai além das classificações gramaticais de que essa se constitui. Assim, no intuito de propiciar aos alunos, de um contexto público de ensino, uma aprendizagem mais significativa, propõe-se aqui uma metodologia diferenciada no ensino da língua inglesa, a partir do uso de textos autênticos (originais, do contexto real), na intenção de construir oportunidades de desenvolver a habilidade de leitura e a capacidade discursiva diante dos significados atribuídos aos textos, motivando o senso crítico-reflexivo dos aprendizes. Para tanto, o suporte teórico adotado, está vinculado às questões de leitura e criticidade, tendo por base os estudos de Freire (1989), Rajagopalan (2003), Lima (2009), Liberali (2009), Marcuschi (2010), dentre outros especialistas, os quais fundamentam a pesquisa. Acredita-se, portanto, que a metodologia adotada se destaca no desenvolver da leitura e da habilidade crítica-discursiva dos indivíduos, além de contribuir, possivelmente, para a sua formação social, política e ideológica.
\end{abstract}

Palavras-chave: Ensino da língua inglesa; Textos autênticos; Criticidade.

\begin{abstract}
This study is based on the assumption that teaching a language goes beyond it grammatical classifications. Thus, in order to encourage students from a public school context, to a more meaningful learning, we propose here a different methodology in the English teaching from the use of authentic texts (original, real context), intending to build opportunities to develop reading skills and the discursive capacity on the meanings attributed to the texts, encouraging student's critical-reflective sense. Thus, the theoretical support adopted, is linked to reading questions and criticality, based on the Freire studies (1989), Rajagopalan (2003), Lima (2009), Liberali (2009), Marcuschi (2010), among others experts, which underlie the research. It is believed, therefore, that the adopted methodology stands out in the development of reading and critical-discursive ability of individuals and contribute possibly to their social, political and ideological.
\end{abstract}

Keywords: English language teaching; Authentic texts; Criticality.

\footnotetext{
${ }^{1}$ Mestranda do Programa de Pós-Graduação em Letras, com ênfase em Cultura, Educação e Linguagem, pela Universidade Estadual do Sudoeste da Bahia (UESB) em Vitória da Conquista. Graduada do Curso de Licenciatura em Letras Língua Inglesa pela Universidade Estadual da Bahia - Campus X (UNEB). Tem interesse na área de Letras, com ênfase no ensino e aprendizagem de Língua Inglesa e formação de professores, além, também, da aplicabilidade da leitura e criticidade no ensino da Língua Inglesa.

2 Doutor em Linguística Aplicada e Estudos da Linguagem pela Pontifícia Universidade Católica de São Paulo (1982) e PósDoutor em Filosofia da Linguagem (Universidade da Califórnia, Berkeley, EUA). Professor Titular na área de Semântica e Pragmática das Línguas Naturais da Universidade Estadual de Campinas.
} 


\section{Revista InterteXto / ISSN: 1981-0601}

\section{v. 9 , n. 1 (2016)}

\section{Considerações Iniciais}

O processo de ensino-aprendizagem de língua estrangeira tem se tornado alvo de muitos debates acadêmicos, sendo tema de pesquisas em diversas abordagens teóricas. Isso se deve ao papel importante que o acesso a uma língua estrangeira ocupa nas interações da sociedade globalizada. As transformações nas teorias do processo de ensino-aprendizagem e dos métodos de ensino de língua estrangeira durante toda a história refletem mudanças nas necessidades da sociedade.

Desse modo, professores, dos diferentes níveis de ensino, procuram refletir sobre ações prováveis para o crescente desenvolvimento do ensino de línguas no contexto educacional, mais especificamente no contexto da escola pública. Por isso, enfrenta-se hoje a necessidade de encontrar outros caminhos que favoreçam a aprendizagem de línguas estrangeiras e, que esta seja significativa e promova mudanças na vida de quem a aprende.

Sendo assim, em meio às estratégias de ensino de línguas estrangeiras, mais especificamente da língua inglesa, é proposta aqui uma metodologia que vise a formação do sujeito baseada em discussões teóricas que ampliem sua visão de mundo, bem como, no estabelecimento de uma interação entre todos os envolvidos no processo, ao ter como instrumento fundamental de ensino o contexto sócio-histórico-cultural.

Dessa forma, a presente pesquisa, busca proporcionar, aos alunos e professores da língua inglesa, da rede pública de ensino, momentos de ensino-aprendizagem que conduza a uma abordagem crítica/reflexiva através do uso de textos autênticos e que oportunize momentos de discussão e interação entre os envolvidos com temas relacionados à sua própria realidade. Além de auxiliar aos professores de inglês a elaborar um material que desmistifique o pensamento de que a prática do ensino de uma língua está voltada apenas para as questões gramaticais com que essa se constitui.

Portanto, esta mesma pesquisa defende a ideia de que a língua, quando considerada como prática social e de natureza sociointeracional, (LIBERALI, 2009) é um instrumento com o qual o aprendiz pode desenvolver também, por meio da interação com o outro, a construção da cidadania pelo acesso a outras culturas e ideologias, e ao seu 


\section{Revista InterteXto / ISSN: 1981-0601}

\section{v. 9 , n. 1 (2016)}

próprio contexto social e histórico, sendo estimulado a refletir e criticar os conteúdos dentro e fora do ambiente escolar.

Busca-se oportunizar, então, a partir dessa nova iniciativa, o desenvolvimento do pensamento crítico/reflexivo tanto do professor quanto do aluno, dando-lhes autonomia para externar ideias e concepções diversas relacionadas a determinadas temáticas apresentadas aos textos. Dessa forma, considera-se importante desenvolver, no ensino da língua inglesa, a consciência crítica num processo reflexivo e racional, através da interação dos sujeitos juntamente com os textos (orais, escritos ou visuais) com vista à construção e reconstrução do significado para produzir conhecimento e cidadania (EDMUNDO, 2010).

Nesse sentido, apresenta-se no próximo tópico o contexto do ensino da língua inglesa no nosso país nos últimos anos.

\section{O atual contexto do ensino da língua inglesa no Brasil}

Nos últimos anos, o ensino de línguas estrangeiras no Brasil passou por muitas modificações tanto no âmbito teórico quanto no âmbito prático (MOITA LOPES, 1996). Com o avanço dos estudos da Linguística Aplicada e o aparecimento de novos métodos e abordagens educacionais, o ensino de língua estrangeira recebe uma visão precisa de linguistas e pesquisadores da área, tornando-se um campo de suma importância para a formação de alunos críticos, construtores de suas próprias realidades. Para mais, o contexto presente, no qual está inserido o ensino de língua estrangeira, tem demandado práticas educacionais que auxiliam para o desenvolvimento de uma consciência reflexiva dos educandos.

Nessa perspectiva, considerar o ensino-aprendizagem de língua estrangeira como um meio de produção e transformação do conhecimento é dar uma nova e próspera visão a esse campo do saber que há anos tem sido sistematicamente relegado a uma posição de desvalorização no contexto educacional brasileiro.

Pode-se afirmar, que por meio do ensino-aprendizagem da língua inglesa é possível proporcionar ao indivíduo uma formação mais ampla, assim como defende o 


\section{Revista InterteXto / ISSN: 1981-0601}

\section{v. 9 , n. $1(2016)$}

PCN (1998) de língua estrangeira, ao estabelecer que, além do conhecimento de uma nova cultura, o ensino de uma língua estrangeira auxilia o educando na construção de uma consciência crítica acerca de sua própria identidade e na percepção das relações ou diferenças que há entre cada costume regional.

Entretanto, por diversos fatores, o ensino da língua inglesa no Brasil tem se mostrado ineficiente, influenciando a sociedade a obter um pensamento de descrédito em relação ao seu aprendizado. Dentre esses fatores, é possível elencar a presença de professores não formados na área e a prática de metodologias ou utilização de materiais didáticos que não atendem às expectativas dos alunos, gerando desvalorização e desinteresse pela disciplina.

Convém salientar, também, que as condições para execução das aulas, na maioria das escolas brasileiras apresentam carga horária reduzida, classes superlotadas e livros didáticos descontextualizados com a realidade dos educandos. Todos esses fatores comprometem a aprendizagem de uma língua estrangeira e inviabilizam o ensino das quatro habilidades comunicativas que compõem o ensino de línguas: fala, compreensão oral, leitura e escrita. Essas questões têm implicado direta e indiretamente na qualidade do ensino-aprendizagem de língua inglesa.

Foi assim, que preocupações relacionadas ao envolvimento do ensino do inglês, principalmente na rede pública de ensino, surgiram, fazendo com que reflexões e novas iniciativas fossem realizadas. Percebe-se, contudo, que o ensino de língua inglesa no contexto atual, configura-se, ainda, marginalizado na educação básica brasileira, posicionando-se entre as disciplinas menos valorizadas pela comunidade estudantil (LEFFA, 2001; PAIVA, 2003).

De acordo com Andrade (2011, p. 09), o ensino do inglês "[...] deve estar embasado em uma concepção de língua mais voltada para a diversidade discursiva que permeia o mundo no qual está inserido o educando". Desse modo, através do caráter social da língua, nota-se que as representações discursivas estão imbricadas às relações de poder político, cultural e ideológico, materializadas pelos indivíduos através da língua. Afinal, não se faz uso da fala, da escrita, ou seja, qual for a modalidade em que uma língua se apresente, meramente utilizando recursos gramaticais e lexicais inconscientemente, sem construir sentidos, sem demonstrar desejos e pontos de vista, sem revelar a identidade de quem fala. 


\section{Revista InterteXto / ISSN: 1981-0601}

\section{v. 9 , n. 1 (2016)}

Partindo da concepção de língua enquanto uma forma de expressão de poder e dominação, busca-se defender o ensino de um idioma através de uma perspectiva crítica que compreenda a língua como discurso e não como uma simples estrutura linguística autônoma. Assim, ao vincular o ensino do inglês com outros aspectos que estão relacionados à língua é possível alcançar uma educação que leve a uma maior participação do aluno em sala de aula através da interação deste com os demais sujeitos inseridos no contexto de ensino.

Considerando, então, as atuais necessidades de mudanças no contexto de ensino da língua inglesa no Brasil, a partir de uma abordagem sociointeracional (tema do próximo tópico), a noção de língua tem se modificado. Não se apresenta apenas como um mero sistema fonológico e morfológico, uma vez que, a língua é um veículo essencial para a comunicação entre os homens e funciona, também, como meio de acesso ao conhecimento. De acordo com Bakhtin (2006), a língua é um produto social e histórico, uma forma de interação social concretizada pelas enunciações.

Em consonância com o pensamento bakhtiniano, o ideal é que todo o processo de ensino-aprendizagem corrobore para o desenvolvimento do indivíduo através da língua e seja envolvido em questões críticas e sociais. Portanto, compreende-se que o ensino de língua estrangeira deva ser contextualizado para que se estabeleçam possibilidades de transformação do sujeito e assim da comunidade na qual está inserido, resultando no enriquecimento da sua formação enquanto ser social.

Diante disso, o ensino de uma língua estrangeira que se caracteriza como elemento de transformação, disposto a dar significado e satisfazer as necessidades reais e cotidianas dos sujeitos, precisa construir perspectivas pautadas nas bases relevantes discutidas anteriormente, ou seja, perceber que o sujeito se relaciona com o mundo e com os outros no mundo, através de uma língua significativa e repleta de possibilidades interpretativas. Dessa forma, é preciso pensar no ensino de língua estrangeira como canal de aprimoramento do conhecimento humano e que, naturalmente, através da linguagem é possível transformar alunos em sujeitos críticos e reflexivos: cidadãos em construção.

\subsection{Prática pedagógica inspirada no sociointeracionismo}




\section{Revista InterteXto / ISSN: 1981-0601}

\section{v. 9 , n. 1 (2016)}

Com os aspectos apresentados no tópico anterior, examinou-se a necessidade de tornar o ensino da língua inglesa mais humanizadora e significativa, distante de uma visão mecânica de ensino, a qual se estabelece fortemente arraigada através da estrutura gramatical que a língua constitui. Kohl (2012) ressalta os pensamentos de dois estudiosos renomados, Piaget e Vygotsky, os quais estabelecem conceitos sobre este tema. Para Piaget, a aprendizagem ocorre através de situações desafiadoras que busquem instigar processos de desiquilíbrios e reequilíbrios, onde a construção do conhecimento não depende apenas da interação com o outro ou simples transmissão de conteúdo, mas sim da participação ativa do sujeito no meio social. Vygotsky, por sua vez, sob outra rica perspectiva, afirma que a teoria sociointeracionista é aquela em que a aprendizagem ocorre através da interação social, onde através das relações os sujeitos trocam ideias, leituras e experiências que culminarão na produção de conhecimentos.

Kohl (2012, p. 3), corroborando com esse pensamento, ressalta, também, de acordo com os estudos de Solé e Coll (2003), que "a aprendizagem tem um caráter ativo e é fruto de uma construção pessoal, na qual não intervém apenas o sujeito que aprende, mas também outros significativos".

Desse modo, ao refletir sobre o ensino da língua inglesa no panorama sociointeracionista, convém destacar que as práticas tecidas em sala de aula devem evidenciar experiências dinâmicas, que movam os educandos à participação ativa nas tarefas propostas. O espaço de sala de aula precisa ter vitalidade, ser comunicativa, de relação social, de construção do conhecimento e de mediação pedagógica, no qual o papel do professor se torna primordial para o progresso expressivo do aluno.

A ação do professor deve compreender uma visão socializadora que se preocupa com propostas pedagógicas diversificadas e que dialogue com o educando, vivificando as interações. Pensar na realização de práticas de leitura, a partir do uso de textos autênticos, que carregam em si uma língua viva e característica do mundo real, pode auxiliar para o alcance de uma abordagem sociointeracionista em sala de aula. Pois, a ação sociointeracionista propõe um trabalho pedagógico que provoque questionamentos, autonomia, percepção, raciocínio, participação, socialização e interatividade. Todas estas ações aplicadas na educação, por meio da leitura, podem influenciar em um ensino mais 


\section{Revista InterteXto / ISSN: 1981-0601}

\section{v. 9 , n. 1 (2016)}

humanizador, concreto e significativo. Essa prática, portanto, trará estímulo ao aluno a sentir-se convidado a participar ativamente do processo ensino-aprendizagem de maneira crítica e transformadora.

\section{Concepções de Leitura e Criticidade: o papel da reflexão crítica no ensino da língua}

Ler, comunicar, relacionar, utilizar a língua e seus aparatos é condição essencial para o desenvolvimento do indivíduo. Ao se relacionar com o mundo esse indivíduo se constrói através de atos culturais, políticos e sociais. De acordo com Rego (2011), ao mesmo tempo em que o ser humano transforma seu meio para atender suas necessidades básicas, transforma-se a si mesmo. Sendo assim, todo o conhecimento adquirido ao longo de sua formação é responsável pela constituição do sujeito na sociedade.

Muito se discute hoje sobre criticidade e formação do cidadão. Freire (1989) preconiza que os sujeitos, antes de qualquer coisa, necessitam ler o mundo ao seu redor, e que essa leitura e esse olhar precedem a leitura da palavra. Desse modo, a capacidade crítica do indivíduo se desenvolveria de maneira mais abrangente e eficaz. Para o autor, a compreensão do texto a ser alcançada por uma leitura reflexiva implica a percepção das relações entre o texto e o contexto. Portanto, Freire (1989) acredita que a construção do cidadão crítico e assim o desenvolvimento da criticidade, parte da premissa do abrir dos olhos para enxergar o mundo em que se vive.

É através de um ensino que preconize o desenvolvimento do senso crítico que o indivíduo poderá ser levado a discutir os problemas que envolvem seu cotidiano e assim, poderá ser capaz de resolvê-los de maneira autônoma. Para Hussein (1982), a criticidade inicia-se na escola com as atividades elementares que levam o aluno a distinguir a realidade da fantasia e, através de comparações entre o que se lê e o que se vive, julgar as informações obtidas entre essas duas perspectivas.

De fato, a habilidade da leitura crítica, se desenvolvida no ambiente educacional, poderá ser benéfica para o crescimento intelectual do aprendiz, o que o fará ser capaz de tomar decisões acertadas, tanto no âmbito social, como no âmbito linguístico. Os PCN 


\section{Revista InterteXto / ISSN: 1981-0601}

\section{v. 9 , n. 1 (2016)}

(1998) de língua estrangeira para o Ensino Fundamental, por exemplo, salientam que a leitura crítica através do ensino de línguas oferece um modo singular para tratar das relações entre a linguagem e o mundo social, já que este é construído pelo próprio discurso. Nesse sentido, os PCN partem para uma discussão acerca da criticidade enquanto formação de um leitor atento que discuta o que lê e não apenas decodifique a mensagem.

Entretanto, discutir criticidade e formação do cidadão, apesar de estar em voga há muito tempo em estudos como o de Freire (1989), os PCN (1998), Liberali (2009), entre outros, só recentemente têm tomado proporções mais notórias no que diz respeito à adoção dessa concepção nos ambientes educacionais. Segundo Jordão (2007), esses ambientes visam 'transformar' os alunos em 'cidadãos críticos e participativos', como se eles não fossem cidadãos antes de passarem pela escola. Ainda segundo a autora, pensar em letramento crítico e/ou criticidade se divide em duas vertentes. A primeira, da qual discorda Jordão, é a corrente marxista que enxerga a criticidade como:

[...] consciência da opressão sofrida por muitos, impetrada por poucos, mas passível de resistência, em movimentos de oposição e luta que, se bem estruturados, levariam à igualdade entre as pessoas; significava que os cidadãos deveriam ser formados para que fossem capazes de lutar contra a hegemonia das minorias e buscar relações de justiça e igualdade entre as pessoas, uma vez que o poder era visto como essencialmente pernicioso. (Jordão, 2007, p. 22)

A segunda corrente é advinda do pensamento de Foucault que apresenta a criticidade sob a perspectiva da relação de poder, a qual gera uma resistência potencialmente positiva e que produz uma série de diferentes conhecimentos modificados ao longo das convivências estabelecidas nas relações entre os sujeitos críticos, dotados de uma capacidade de examinar e inferir criticamente nas diversas situações cotidianas.

Nessa última perspectiva, com a qual corrobora este trabalho, os sujeitos que estão no mundo e localizados nele partem em direção ao outro com o seu legado, sua história e conhecimentos socioculturais adquiridos ao longo de sua vida. Em contrapartida, recebem outros valores que os modificam e os tornam conhecedores de novos saberes. Nesse desenrolar de relações entre os sujeitos, que podem ser global e 


\section{Revista InterteXto / ISSN: 1981-0601}

\section{v. 9 , n. 1 (2016)}

local, "onde o global está localizado e o local está globalizado" (ROBERTSON, 1992 apud KUMARAVADIVELU 2006, p.134), é que a criticidade se manifesta, pois, ao se deparar com discursos e posições hierarquizadas atuantes, os sujeitos discutem, ponderam e se colocam criticamente, através do uso da linguagem e seus aparatos no mundo.

\section{Contextualizando o ensino pela autenticidade textual}

O contexto atual do ensino de língua inglesa no Brasil, influenciado por uma tendência sócio-histórica e cultural, objetiva formar alunos críticos e participativos na sociedade por meio de estudos no campo da Linguística Aplicada Crítica (LAC). Esta disciplina de estudos da linguagem, defendida por autores como Pennycook (1998), Rajagopalan (2003) e Kumaravadevelu (2006) propõe uma visão reflexiva e transgressiva em torno da língua e seu ensino através da abordagem de temas sobre identidade, etnia, gênero, política, etc.

De acordo com essa proposta de um ensino de língua que privilegie a criticidade do educando, alguns autores (FAIRCLOUGH, 1999; LIMA, 2009; MARCUSCHI, 2010) acreditam ser indispensável que o processo de ensino seja organizado em torno do estudo do texto, pois, a partir dele, diversas dimensões, metodologias e habilidades podem ser desenvolvidas, por exemplo, no âmbito lexical, gramatical, cultural, político, ideológico, etc. Para tanto, faz-se necessário definir o que é texto.

Sabe-se que a ideia de texto, no senso comum, está bastante arraigada à modalidade escrita, primeiramente devido ao advento da imprensa e mais recentemente com o surgimento da internet, onde circulam diversos gêneros textuais. Entretanto, Fiorin e Platão (2003) afirmam que o texto não é apenas um conjunto de frases e vai além do campo meramente linguístico, das palavras, pois, todo texto possui um enunciado dentro de uma discussão mais ampla.

Orlandi (2001) também apresenta, a partir da Análise do Discurso, uma definição de texto, seja oral ou escrito, segundo sua unidade significativa, como a materialização do discurso (efeito de sentidos entre locutores). Entretanto, texto não se caracteriza apenas 


\section{Revista InterteXto / ISSN: 1981-0601}

\section{v. 9 , n. 1 (2016)}

pela sua forma, tipo e gênero, mas pelas ideias que o constitui, pelos significados criados pelos autores e leitores. Segundo Orlandi, para o leitor, texto é:

[...] a unidade empírica que ele tem diante de si, feita de som, letra, imagem, sequências com uma extensão, (imaginariamente) com começo, meio e fim e que tem um autor que se representa em sua unidade, na origem do texto, "dando"-Ihe coerência, progressão e finalidade. (Orlandi, 2001, p. 64)

Assim, é impossível não atrelar os sujeitos sociais à noção de texto. Lima (2009p. 48) afirma que "fora do texto - e do contexto - não existe significado possível". Portanto, ser capaz de ler e compreender o texto dentro de uma escala mais abrangente significa alcançar o nível do discurso e suas implicações socioculturais, políticas, linguísticas e estéticas. A significação do texto em suas várias formas e por meio de vários canais, impresso ou digital, oral em diversos gêneros depende da interação com o leitor. Para Lapkoski,

O leitor, portanto, é a peça principal no processo de leitura, sem o qual não há razão para o texto, nem construção de sentido possível. É a partir do leitor que um texto passa a existir, de fato, como veículo transmissor de mensagens. E, considerando que cada leitor constrói sentidos novos a partir do seu conhecimento prévio e que este conhecimento é diferente em cada leitor, podemos entender que toda leitura que se faz de um mesmo texto é particular e única. (Lapkoski, 2005, p.7)

Dessa forma, essa noção de texto se relaciona com a de autenticidade, tanto pela visão do leitor quanto do autor. É uma maneira de aproximar o aprendiz do uso real da língua-alvo e do seu contexto social do ensino. Pois, dentre diversas definições do que seja texto autêntico, as visões de Harmer e Numan (1989 apud OLIVEIRA, 2005), especialmente, corroboram com os objetivos desta pesquisa. Os autores afirmam que textos autênticos são aqueles especificamente criados para falantes nativos, ou seja, textos reais, não produzidos para fins de ensino-aprendizagem de língua, mas para falantes da língua em questão. 


\section{Revista InterteXto / ISSN: 1981-0601}

\section{v. 9 , n. 1 (2016)}

A autenticidade dos textos, porém, não deve referir-se somente à sua produção a partir do uso da língua em si, em um determinado contexto real de comunicação e à sua forma, mas também à relevância que esse texto apresentará para o leitor. Será ele real em termos de compreensão linguística e de significação das ideias, pois, são os leitores que darão sentido e gradual autenticidade ao texto através da interação e engajamento discursivo. Afinal, a partir do momento que o texto é retirado do seu contexto real e levado para a sala de aula, pode-se perder a autenticidade em termos de função. De acordo com Widdowson (1994), o texto pode ser autêntico, por exemplo, de jornais e revistas, em termos linguísticos, mas se não tem relevância para a realidade e contexto cultural, deixa de ser autêntico para o leitor.

Assim, como todo texto se insere em algum determinado gênero, o estudo de diversos gêneros textuais torna-se uma importante ferramenta, tanto para conhecimento, produção e compreensão linguística/textual, quanto para atingir o objetivo de um letramento crítico no ensino de língua estrangeira. De acordo com Marcuschi (2010, p. 19), "gêneros textuais são entidades sociodiscursivas e formas de ação social incontornáveis em qualquer situação comunicativa". A todo tempo e lugar, onde houver indivíduos interagindo socialmente encontram-se textos em suas diversas modalidades, ou seja, gêneros textuais. Estes, por serem objetos sociais, se caracterizam pela dinamicidade e inovação, pois, estão sempre se adaptando e se recriando de acordo com as mudanças da sociedade.

Sendo assim, é relevante trabalhar com textos materializados na vida diária, tais como: vídeos de notícias, contos, séries, textos jornalísticos, charges, entre outros. Pois, nesse caminho é que o ensino de língua inglesa pode ser desenvolvido, sempre levando em consideração os enunciados cotidianos e significativos para os sujeitos participantes desse processo. De acordo com Lima,

O ensino de línguas estrangeiras deve ser organizado em torno do estudo do texto (textos de todos os tipos e gêneros, em seu sentido mais amplo e profundo, no nível do discurso, implicando o conhecimento da noção dinâmica de textualidade e discursividade), uma vez que o texto faz girar todas as dimensões desse ensino: lexical, gramatical, semântica, estética, política, cultural, etc. (Lima, 2009, p. 51) 


\section{Revista InterteXto / ISSN: 1981-0601}

v. 9 , n. 1 (2016)

Diante disso, uma aula de língua estrangeira pode tratar de diversos conteúdos ideológicos, culturais, históricos e sociais - não somente gramaticais, mas que sejam significativos para a realidade do aluno e o façam refletir criticamente sobre seu mundo a partir da leitura de diferentes textos.

\section{Pela busca de uma prática significativa}

A partir dos levantamentos teóricos neste trabalho salienta-se a necessidade de explorar uma metodologia que oportunize discussões críticas e reflexivas em sala de aula de língua inglesa, em um contexto público de ensino, através do uso de textos autênticos, tais como charges, vídeos, textos jornalísticos, etc., os quais possibilitem um fazer pedagógico para além do exercício da leitura e oralidade em língua inglesa entre seus participantes, mas também a troca de experiências, conhecimentos, e a construção de significados e reflexão crítica por meio da discussão de diversos textos. E, é nesse cenário que se objetiva utilizar a língua inglesa como um instrumento para a reflexão de temas de caráter político-social, tais como: classe, etnia, gênero, sexualidade, etc.

Sendo assim, através de atividades que priorizem a língua/contexto "real" (HARMER, 2001) dos aprendizes que é possível alcançar de forma mais prazerosa e significativa, a participação dos educandos, com discussões de temas que valorizassem o seu conhecimento de mundo para facilitar a interação dos mesmos com o meio social. Nesse caso, há três objetivos fundamentais comuns que orientam a metodologia dos encontros em sala de aula, a saber: a) expor os alunos a uma variedade de textos; b) introduzir e aperfeiçoar habilidades de organização textual dos estudantes; c) orientar os alunos na prática de leitura e ação discursiva de forma crítica e reflexiva.

A abordagem apresentada neste estudo, portanto, vincula-se à busca de uma intervenção crítica no contexto de ensino-aprendizagem da língua inglesa, especialmente em termos de capacidade dos alunos para adoptar uma abordagem mais reflexiva para os textos que leem e da forma com que eles expressam suas ideias.

De modo geral, compreende-se que a presença dessa prática em sala de aula se encontra em evidência no contexto acadêmico e, seus estudos, em relação à sua aplicabilidade e relevância, vêm sendo realizados e discutidos, primordialmente, na área da Linguística Aplicada Crítica (LAC) ao adotar uma postura mais crítica e 


\section{Revista InterteXto / ISSN: 1981-0601}

\section{v. 9 , n. 1 (2016)}

compromissada com as questões sociais e relativas à prática da linguagem. Esta disciplina de estudos da linguagem, defendida por autores como Pennycook (1998), Rajagopalan (2003) e Kumaravadevelu (2006) propõe uma visão reflexiva e transgressiva em torno da língua e seu ensino através da abordagem de temas sobre identidade, etnia, gênero, política, etc.

A LAC, portanto, entende que a relação do aluno com as suas mais diferentes propriedades - a língua(gem), sua ideologia, sua cultura, etc. - extrapola a sala de aula e o universo escolar e acompanha o indivíduo nas diversas esferas de relação social em que ele está inserido, a fim de se ter, em seus registros de intervenção social, uma compreensão, se não integral, ao menos mais próxima do contexto sociocultural em que se inserem as práticas discursivas e o aprendizado escolar.

\section{Considerações finais}

Buscar um avanço em direção a melhorias no âmbito educacional é condição essencial no fazer pedagógico do profissional da educação. Nesse sentido, essa pesquisa, por meio das discussões apresentadas, procurou sugerir uma estratégia possível para o bom desenvolvimento do aprendiz da língua inglesa. Sendo assim, delimitou-se como objeto de pesquisa, o desenvolvimento da criticidade, através da leitura de textos autênticos, com o intuito de demonstrar que por meio desses textos nos diversos gêneros, o leitor será capaz de aprimorar sua capacidade discursiva e reflexiva.

Essa pesquisa, portanto, parte da indagação de como os textos autênticos podem auxiliar no desenvolvimento da criticidade no ensino de língua inglesa, e se é possível colaborar para a boa formação do cidadão através do ensino regular de um contexto público. Pois, acredita-se que uma abordagem de ensino centrada na utilização de textos autênticos em língua inglesa pode tornar a aprendizagem mais significativa e situada ao contexto social dos participantes, além de possibilitar uma leitura mais ampla dos significados dos discursos presentes nos textos.

Vale salientar que, para o desenvolvimento da criticidade no ensino da língua inglesa, parte do professor assumir uma postura reflexiva sobre sua própria metodologia e se conscientizar da sua responsabilidade social por influenciar na formação da identidade 


\section{Revista InterteXto / ISSN: 1981-0601}

\section{v. 9 , n. 1 (2016)}

dos aprendizes. É como mediador do conhecimento que o professor pode incentivar o aluno a adquirir uma postura crítica e reflexiva perante os textos e suas ideologias, o que pode motivar a autonomia desse indivíduo.

Dessa forma, compreende-se que, desde a formação de professores até a prática do ensino de língua inglesa nas escolas, é preciso adotar um caráter crítico que privilegie o contexto sócio-histórico e cultural do aprendiz e extrapole o modelo tradicional de ensino dessa língua, pautado nos aspectos gramaticais.

Argumentou-se, aqui, então, que as práticas pedagógicas estabelecidas na perspectiva da interação podem se converter em excelentes estratégias de incentivo ao desenvolvimento potencial dos educandos, fortalecendo a rede interacional entre o professor, alunos e o conteúdo dos textos.

Nesse sentido, através da prática desta metodologia, com o uso de textos autênticos, é possível apreender os efeitos de vários tipos de interação pedagógica que ocorrem no processo de leitura crítica, a qual parte de uma interpretação textual, para então chegar a uma interpretação do discurso que leva a um posicionamento de aliança ou de resistência.

Considera-se, aqui, também, que o trabalho desenvolvido pelo professor, à luz do sociointeracionismo, subentende o desenvolvimento cognitivo do indivíduo de maneira efetiva, através da intensa troca entre os sujeitos e o objeto da aprendizagem, a fim de propiciar aos cidadãos uma aprendizagem interessante, reflexiva e consciente, distante de uma ideia mecânica de ensino; o que se constitui a partir do processo de interação. Assim, enquadrar esse significado de uma abordagem sociointeracionista para dentro da sala de aula de língua inglesa, capacita e transforma as situações interacionais, além de influenciar a busca e a prática de uma metodologia mais dinâmica no processo do ensinar e do aprender.

Neste caminho, procurou-se evidenciar a demanda de práticas educativas diferenciadas, que extrapolem toda a forma de condicionamento e proporcione a autonomia, a construção do conhecimento e o desenvolvimento cognitivo do aluno, um verdadeiro despertar das inteligências.

\section{Referências}


ANDRADE, C. S. O ensino interdisciplinar de língua inglesa. Conceição do Coité, 2011. Disponível em: <http://pt.slideshare.net/BPJCA/o-ensino-interdisciplinar-de-linguainglesa>. Acesso em: 02 abr. 2015.

BAKHTIN, M. Marxismo e filosofia da linguagem. Hucitec: 12 ed. 2006. p. 124. Disponível em:

<http://www.fecra.edu.br/admin/arquivos/MARXISMO_E_FILOSOFIA_DA_LINGUAGEM.p df>. Acesso em: 20 abr. 2015.

BRASIL. Ministério da Educação. Lei de Diretrizes e Bases da Educação Nacional LDB. Brasília, DF. Lei n. 9.394/96. Disponível em:

<http://www.planalto.gov.br/ccivil_03/Leis/L9394.htm>. Acesso 20 abr. 2015.

BRASIL. Secretaria de Educação Fundamental. Parâmetros curriculares nacionais: terceiro e quarto ciclos do ensino fundamental. Língua estrangeira. Brasília: MEC/SEF, 1998.

BRASIL. Ministério da Educação. Orientações curriculares para o ensino médio OCEM. Linguagens, códigos e suas tecnologias. Secretaria da Educação Básica, 2006. Brasília, DF. Disponível em:

<http://www.letras.ufmg.br/profs/reinildes/dados/arquivos/ocem.pdf>. Acesso em: 19 abr. 2015.

EDMUNDO, E. S. G. O ensino de inglês na escola pública sob a perspectiva do letramento crítico. Curitiba, 2010. Disponível em:

<http://dspace.c3sl.ufpr.br/dspace/bitstream/handle/1884/24961/DISSERTACAO\%20ELIA NA\%20SANTIAGO.pdf?sequence=1>. Acesso em: 23 abr. 2015.

FAIRCLOUGH, N. Global capitalism and critical awareness of language. Landcaster University, v. 8, n. 2, 1999. Disponível em:

<http://eprints.lancs.ac.uk/8546/1/la0080071.pdf>. Acesso em: 19 abr. 2015.

FIORIN, J. L.; PLATÃO, F. Para entender o texto: leitura e redação. 16 ed. São Paulo: Ática, 2003.

FREIRE, P. A importância do ato de ler: em três artigos que se completam. 23 ed. São Paulo: Autores Associados. Cortez, 1989.

HUSSEIN, C. L. Leitura crítica: ensino e aprendizagem. 1982. Disponível em: <carmenluciahussein.com.br/pagina.php?id=17>. Acesso em: 27 abr. 2015.

JORDÃO, C. M. As lentes do discurso: letramento e criticidade no mundo digital. Campinas, v. 46, n. 1, 2007. Disponível em:

<http://revistas.iel.unicamp.br/index.php/tla/article/view/1846>. Acesso em: 27 abr. 2015.

KOHL, M. Piaget - Vygotsky: Novas contribuições para o Debate, RJ: Ática, 2012. 
KUMARAVADIVELU, B. A linguística aplicada na era da globalização. In: MOITA LOPES, L. P. (org.). Por uma linguística aplicada indisciplinar. São Paulo: Parábola Editorial, 2006.

LAPKOSKI, G. A. O. A avaliação de leitura em inglês como língua estrangeira no centro de línguas da UFPR - CELIN. Curitiba, 2005. Disponível em:

<http://www.humanas.ufpr.br/portal/arquivos/Graziella\%20Araujo\%20de\%200liveira\%20L apkoski.pdf>. Acesso em: 27 abr. 2015.

LEFFA, V. J. Aspectos políticos da formação do professor de línguas estrangeiras. In: . (Org.). O professor de línguas estrangeiras: construindo a profissão. Pelotas, 2001, v. 1, p. 333-355.

LIBERALI, F. C. Atividade social nas aulas de língua estrangeira. São Paulo: MODERNA, 2009.

LIMA, L. R. Texto e discurso no ensino de inglês como língua estrangeira. In: LIMA, D. C. (org.). Ensino aprendizagem de língua inglesa: conversas com especialistas. São Paulo: Parábola Editorial, 2009. p. 47-51.

MARCUSCHI, L. A. Gêneros textuais: definição e funcionalidade. In: Dionisio, A. P.; MACHADO, A. R.; BEZERRA, M. A. (orgs.). Gêneros textuais e ensino. São Paulo: Parábola Editorial, 2010. p. 19-38.

MOITA LOPES, Luiz Paulo. Oficina de linguística aplicada: a natureza social e educacional dos processos de ensino-aprendizagem de línguas. Campinas, SP: Mercado das Letras, 1996.

OLIVEIRA, E. L. R. Textos autênticos em aulas de língua inglesa: analisando o seu uso no contexto da escola pública. Uberlândia, 2005. Disponível em:

<http://repositorio.ufu.br/bitstream/123456789/2135/1/TextosAut\%C3\%AAnticosAulas.pdf> . Acesso em: 20 abr. 2015.

ORLANDI, E. P. Discurso e texto: formulação e circulação dos sentidos. São Paulo: Pontes, 2001.

PAIVA, V. L. M. de O. A LDB e a legislação vigente sobre o ensino e a formação de professor de língua inglesa. In: STEVENS, C. M. T.; CUNHA, M. J. Caminhos e colheitas: ensino e pesquisa na área de inglês no Brasil. Brasília: Unb, 2003. p. 53-84.

PENNYCOOK, A. A linguística aplicada dos anos 90: em defesa de uma abordagem crítica. In: SIGNORINI, I.; CAVALCANTI, M. C. (orgs.). Linguística aplicada e transdisciplinaridade. Campinas: Mercado das Letras, 1998. p. 23-49.

RAJAGOPALAN, K. Por uma linguística crítica: linguagem, identidade e questão ética. São Paulo: Parábola Editorial, 2003. 
Revista InterteXto / ISSN: 1981-0601

v. 9 , n. 1 (2016)

REGO, T. C. Vygotsky: uma perspectiva histórico-cultural da educação. 22 ed. Rio de Janeiro: Vozes, 2011.

WIDDOWSON, H. G. Autonomous learner and authentic language. In: LEFFA, V. J. Autonomy in language learning. Porto Alegre: UFRGS, 1994. p. 381-394.

Artigo recebido em 07/04/2016

Artigo aceito em 29/06/2016 